\title{
Coragem e Vergonha. Os mortos e a vingança no sertão de Pernambuco
}

\author{
JORGE MATTAR VILLELA
}

\section{Introdução}

$\mathrm{O}$ artigo que se segue visa descrever analiticamente as implicações das vidas dos mortos nas vidas dos vivos. Ele é o retorno ao material utilizado em minha tese de doutorado escrita há 16 anos sobre vingança no sertão de Pernambuco, onde faço pesquisa de campo desde $1999^{1}$. Sua especificidade repousa nas relações dos vivos com os seus mortos nos processo de vingança. Sua hipótese de fundo desdobra-se em dois aspectos: 1 . O problema das reputações dos descendentes das pessoas cujos nomes constam em processos judiciais, quer dizer, que foram perseguidos pela justiça e pela polícia e a consequente ambiguidade das avaliações morais, positiva e negativa; 2 . As repercussões das respostas dos vivos ao apelo dos mortos em virtude das vinganças na gestão da segurança pública e na gestão da justiça.

A metodologia, por sua vez, bifurca-se em duas abordagens. Uma delas prende-se ao tratamento dispensado à massa de documentos voltados à preocupação com a segurança pública ameaçada pelas "grandes questões" (brigas entre famílias cujos recursos disponíveis ampliam-nas em dimensão e alcance imprevisíveis até tornarem-se ameaças à "ordem pública” e receberem políticas de segurança especificamente voltadas ao seu combate), tão históricas quanto atuais no sertão de Pernambuco. A segunda diz respeito ao impacto no cotidiano dos e das sertanejas implicadas nos esquemas de vingança.

Ao longo de minha pesquisa para o doutorado (Villela 2003) reuni uma vasta quantidade de material resultante desse fenômeno, existente em diversas partes do mundo e em vários momentos históricos, que é a vingança. Esse material, no que se circunscreve ao Sertão, consiste em: 1. em centenas de processos crime à época estocados (dizer arquivados seria uma imprecisão) nas comarcas sertanejas de

1 Municípios de Triunfo, Serra Talhada e Floresta, situados, respectivamente, na mesorregião do São Francisco e do Sertão, microrregiões de Itaparica e do Pajeú. Populações de, aproximadamente, 30 mil, 80 mil e 25 mil habitantes. Carnaubeira da Penha, acrescentada à circunscrição da pesquisa a partir de 2007, é um antigo distrito de Floresta emancipado em 1991. População de aproximadamente 13 mil habitantes. Esse artigo é parte dos resultados da pesquisa financiada pela FAPESP, entre 2016 e 2018, no âmbito dos Auxílios Regulares, projeto número 2016/03846-6. 
Serra Talhada, Triunfo e Floresta (Villela 2004)²; 2. nos relatórios de autoridades de níveis municipais e estaduais competentes pela administração da violência, da ordem pública e da segurança individual e, enfim; 3. num vasto conjunto de ações policiais, como telegramas trocados durante os deslocamentos de forças policiais volantes, planos de ação e acordos interestaduais para a repressão do "banditismo no interior", relatórios dos delegados dos municípios e dos juízes das comarcas circunscritas nesta pesquisa. A hipótese central era que, tanto hoje quanto antes, uma parte desses planos da segurança pública e de sua organização consistia em respostas aos esquemas de vingança e de seus desdobramentos sob a forma de delinquência.

A bibliografia a respeito da antropologia dos documentos e dos arquivos amplia-se vastamente desde a década de 1990 (e.g. Buckland 1997; Bevilaqua 2003; Cunha 2004; Riles 2006 e 2013; Morawska 2015; Munhoz 2013 e 2017). Essa vasta bibliografia, cuja lista acima é apenas um pequeno exemplo e cuja confecção é o efeito de preferencias e adesões, duas grandes questões se desprendem. Uma delas é o da agência dos documentos que deixam de ser objetos elaborados por sujeitos neutros e cuja existência justifica-se por sua condição de testemunha do passado, como uma memória garantida pela escrita (a relação preferida que a ciência da história moderna estabelece com os documentos). Eles passam à condição de sujeitos de factualização do passado. Mas também tornam-se sujeitos que "fazem fazer", para empregar a expressão célebre de Latour (1999).

Minha abordagem dos documentos é semelhante à adotada por Munhoz (2017), que aponta para sua elaboração por técnicos das medidas socioeducativas no sentido de conferir a eles uma agência que, ao serem lidos pelos juízes de menores, supera a ação de seus autores. Os autores dos processos crime e dos relatórios de chefes de polícia, dos juízes e delegados municipais e dos governadores de Pernambuco, a documentação de que dispus e que são o fulcro documental de minha pesquisa de doutorado, visavam obter resultados a partir deles. Os processos que examinei relatam ataques físicos ou morais - ainda que o físico e o moral fossem com frequência de difícil distinção - de sentido provocativo e desmoralizante e que precipitavam, mais cedo ou mais tarde, atentados violentos contra a vida, impondo aos envolvidos um roteiro escrito pelas mãos das autoridades jurídico-policiais que, se não engajadas diretamente no caso, dispunham das peças de um quebra-cabeças cujos desenhos permitiam diversos encaixes.

Essa é uma boa definição de como, metodologicamente, uma antropologia dos documentos lida com essas peças, com esse estilo narrativo, essa expressão jurídico-cartorial dos acontecimentos, que são os processos judiciais. Essa abordagem metodológica dos processos permite escapar de uma armadilha: transpor aos documentos os fatos que eles não contêm, metamorfoseando relatos atuais sobre o passado em dados contemporâneos aos processos, misturando a memória atual com o transcrito no calor da hora, fazendo penetrar, uma na outra, paixões de naturezas distintas.

O mesmo se pode dizer dos relatórios redigidos pelas autoridades da segurança pública. Eles revelavam o trânsito entre instituições de diversos níveis de poder e abrangência. Recebidas as mensagens,

2 A partir de 2005, todos os processos extintos de todas as comarcas de Pernambuco foram transferidos para o Memorial do Tribunal de Justiça de Pernambuco em Recife. 
eram encaminhadas ao nível hierárquico superior. Elas eram elaboradas in situ e pretendiam não meramente informar, mas formar uma imagem, extrair resultados, produzir tendências nas instâncias de decisão mais abrangentes. Por sua vez, os relatórios produzidos nessas instâncias eram uma edição cuidada a ser reportada às assembleias de nível estadual e ao governador do estado. Eles também visavam extrair resultados na gestão da segurança e da ordem pública e, como corolário, efeitos de poder. Sem a presunção da neutralidade e de sua natureza de constatação factual do passado, a abordagem metodológica de uma antropologia dos documentos, do arquivo e da burocracia exige que as tomemos como elas são: modalidade de exercício de formulação de políticas, de programas, de tendências (Morawska 2014).

O segundo conjunto do material é o resultante desse complexo de técnicas em certos casos mal definido e agrupadas relativamente ao acaso dos encontros a que a antropologia, historicamente e para a sua própria constituição como atividade acadêmica, se deu ao luxo de chamar "pesquisa de campo". Tentarei especificar o que em minha pesquisa essa expressão quer dizer.

Uma das técnicas de pesquisa que emprego entre meus amigos e amigas no sertão de Pernambuco (vale retomar a informação de que faço pesquisa lá há quase 20 anos e que tenho, portanto, vários amigos e amigas, além das crianças de então que hoje são homens e mulheres adultos e com seus próprios filhos e filhas) tem-se baseado no mero reencontro de pessoas que se querem bem e se conhecem há muito tempo. Conversas dirigidas às nossas vidas pessoais, à das nossas famílias, relatos das novidades minhas, deles e delas. No ambiente urbano da pesquisa, o decorrer dos dias me faz viver o cotidiano das demais pessoas e me expõe aos encontros a que elas se expõem e permitem que eu presencie e interaja também. Essa modalidade de contato me faz expandir as conexões de pesquisa, sobretudo porque algumas das minhas amizades quando visitadas por pessoas que eu não conheço me apresentam junto com as minhas intenções de pesquisa atuais.

A segunda técnica é fazer deliberadamente a conversa girar em torno de um dos subtemas da pesquisa - seja individual ou coletivamente. Segundo minha experiência, as mais rentáveis conversas ocorrem coletivamente com pessoas de casas diferentes, em público. É evidente que temas delicados ou segredos não circulam nesses ambientes, mas eles favorecem a pesquisa por conta do debate, da controvérsia e da discordância.

Finalmente, e raramente, lanço mão, sempre com objetivos muito específicos, de entrevistas. Elas ocorrem sobretudo, mas não exclusivamente, com pessoas cujo conhecimento meu é recente e que exigem uma relação mais formal de pesquisa. As entrevistas com pessoas próximas visam o esclarecimento de pontos obscuros ou delicados de certas situações. Elas servem, portanto, mais como detalhamento do que como produtoras de dados de pesquisa, pois, como pontos delicados e segredos muitas vezes revelados exclusivamente a mim, não podem ser publicados. Funcionam, no entanto, como diretrizes que me impedem de falsificar ou de interpretar equivocadamente cenas que testemunho ou conversas que ouço em diálogos de que participo apenas como coadjuvante. Uma terceira modalidade de entrevista será mencionada no parágrafo seguinte.

No interior, ainda, dessa modalidade, efetuei pesquisa de campo durante ao menos uma "época dos tribunais". Já estive no sertão de Pernambuco em mais de uma dessas épocas. Nem em todos os municípios ela é vivida como tal, coletivamente, por uma parte significativa da população urbana e outras 
variações de envolvimento podem ser constatadas segundo a relevância e a publicidade dos processos em questão e dos envolvidos nele. Nessa modalidade incluem-se entrevistas agendadas com juízes/as e promotoras/es. Tenho, também, contato já antigo com a delegada de dois dos municípios que certamente tem sido parte central nesta vertente da pesquisa.

\section{Atitudes Violentas}

No caso do sertão de Pernambuco, o que justifica uma atitude de vingança que recorra a atos violentos são os laços familiares. Com alguma frequência, uma pessoa, ou um grupo de pessoas, envolvida num episódio compreendido como um insulto, é motivada pelo sangue a reagir adequadamente a esta afronta ${ }^{3}$. Quer dizer, a motivação é da ordem do parentesco; o que não é tudo, nem sequer muito. Parente, assim como família, são expressões muito complexas, no sentido em que são compostas por muitas partes, entre elas o já mencionado sangue.

O esquema das vinganças que ocorre ali ao menos há dois séculos pode ser descrito pelas expressões "solidariedade ativa e passiva", celebrizadas na literatura antropológica que explora o tema das vinganças de sangue pelo mundo, fundadas por Radcliffe-Brown (1940) e continuadas pela antropologia política herdeira das coletâneas de artigos a respeito dos sistemas políticos africanos (Evans-Pritchard e Fortes 1940; Middleton e Tait 1958), sob o nome de "self help". O desenvolvimento da noção e sua adaptação para ambientes como as "sociedades mediterrâneas" atribuíram à vingança, no discurso antropológico, a mesma característica que a antropologia da área mediterrânica atribuiu à patronagem: a de "addendum" (Landé 1977). A vingança nas sociedades de Estado foi considerada uma impropriedade, uma inadequação a um ambiente jurídico cuja execução da justiça fora centralizada e atua numa posição intermediária em relação às partes em conflito. Em certos casos, o discurso antropológico compreendeu que a vingança efetua o desequilíbrio nas forças da justiça por meio da corrupção ou da influência espúria da violência ou dos recursos financeiros (Blok 1974; Otterbein 1994). Veremos que, embora não incorreta, essa abordagem mostra-se insuficiente. Gostaria, antes de justificar essa objeção, de me deter no esquema de vingança específico do sertão de Pernambuco.

A expectativa e a existência desse esquema de vinganças no sertão de Pernambuco ocorre por meio de várias fórmulas discursivas, entre as quais eu destacaria duas, cujo sentido é o mesmo. Ao constatar que um indivíduo de uma família de fama (cuja reputação força-o a responder com violência aos insultos sofridos) morreu ou foi vítima de um dano grave, costuma-se dizer que a retaliação implicará na morte de todos os integrantes da família agressora, "que vão morrer todos, até as galinhas", que "vão matar até os pagãos" ou que vão matar "até a mãe do calor dos figos"; expressão de significado obscuro mesmo para os e as sertanejas. Essa fama é fundamental para estabelecer uma primeira relação entre vivos e mortos no esquema das vinganças que é a da herança e da composição de si. E era, no passado,

3 As palavras em itálico referem-se ao ecossistema nocional empregado no Sertão. As aspas simples, a citações referentes ao material de pesquisa; as duplas, a citações de autores e autoras. 
um critério para a obtenção de cargos municipais no policiamento urbano ou rural, como no caso dos Inspetores de Quarteirão (Villela 2004).

Qualquer indivíduo é compreensível para si e para os outros por conta das relações de parentesco e de ascendência que o compõem e, por conseguinte, pelo sangue que corre em suas veias. A composição pelos mortos sob os quais, de acordo com a imagem de uma árvore invertida, uma pessoa se encontra como descendente e suas raízes acima dela, formula, portanto, um certo repertório de respostas possíveis a atos violentos. Essa implicação, no entanto, não é imediata e nem dada. Ela é repleta de variações e costuma ser imprevisível, resultado de uma certa instabilidade do parentesco sertanejo (Villela 2009; Marques 2013; Villela e Marques 2016).

O primeiro impacto, portanto, dos mortos nas vidas dos vivos é a própria composição desses por aqueles pela via do sangue. O segundo impacto dos mortos nas vidas dos vivos no esquema das vinganças é o da exigência da ação vindicativa. É preciso punir, extrair alguma satisfação ou sofrimento equivalente de quem tirou a vida de um parente; assim como é preciso silenciar as conversas, quer dizer, os rumores acerca da inação da família, mas também as bravatas dos matadores. O que implica um terceiro elemento, dado que se vive sob uma legislação que previne ou proíbe que se lance mão diretamente e sem mediação do sistema de compensações por danos sofridos, cujo conteúdo prevê idealmente a distinção entre justiça e vingança. Quem mata por vingança (ou por qualquer motivo, mas para este artigo só as vinganças importam) torna-se imediatamente um perseguido pelo Ministério Público, o responsável pelas denúncias de homicídio e atentado contra a vida segundo as leis brasileiras. A perseguição pela justiça, a proteção da família ou a clandestinidade fazem com que a vingança no sertão de Pernambuco, assim como as relações de parentesco, torne-se vetor de bando, pois é nessas relações que a clandestinidade, na falta de outros meios econômicos, poderá se ancorar. Essa é uma forma, nem sempre possível, de evitar que a clandestinidade vire delinquência. Um dos mais importantes fenômenos de banditismo das Américas, o cangaço de Lampião, decorreu desse esquema e seus primeiros processos encontravam-se na comarca de Serra Talhada quando da minha pesquisa de campo para o doutorado (Villela 2004 e 2011).

A clandestinidade e o banditismo, a perseguição pela justiça e pela política, a possibilidade aberta para o caminho da delinquência e para a vida carcerária, são problemas a serem enfrentados nesse artigo. Ele impõe a compreensão da ambiguidade do que se entende por coragem e por vergonha no sertão de Pernambuco, conforme veremos a seguir.

\section{A ambiguidade da vida em armas}

O problema da ambiguidade da avaliação das pessoas envolvidas em mortes por vingança apareceu pela primeira vez em duas conversas na época em que, fazendo pesquisa em processos antigos, verifiquei que a menção sigilosa que eu fazia a amigos e amigas descendentes de pessoas envolvidas em brigas, vítimas ou algozes, nos processos não as envergonhavam, mas provocavam nelas e em parentes para quem as divulgavam, certo orgulho ou humor. Minha surpresa deveu-se à recorrência das críticas 
feitas a pessoas e seus atos violentos. Não obstante, o último período de campo efetuado em 2017, tornou ainda mais clara a ambiguidade da relação dos vivos com os atos violentos de seus antepassados.

Uma das condições de compreensão dessa ambiguidade é a oposição brabo-manso. Ser violento na discursividade elogiosa ganha o aspecto do ser valente. Valente, por sua vez, opõe-se, em princípio, a manso, que também se opõe a brabo; uma oposição correlativa à que se faz aos animais, sobretudo ao bois, mas também a certas plantas ou a toda a vegetação circundante, a caatinga. Também nesses casos a ambiguidade e a labilidade dos sentidos positivo e negativo conferidos a essas palavras é evidente. Assim, valente pode ser também manso, sendo este último o mais perigoso modo de ser valente. Valente, no entanto, quando compõe com manso, opõe-se a violento, mas também a ignorante. É quem não quer briga, mas que 'se mexer com ele' ou 'com alguém dele é pior que uma cobra'. A essas pessoas é atribuída uma avaliação moral positiva, pois congregam em si as duas características mais bem valoradas dos sertanejos: a modéstia nos atos e palavras, a moderação do espírito, por um lado; a capacidade de reação a altura dos desafios impostos ao longo de sua vida, por outro. São pessoas prontas para 'qualquer eventualidade' e que não se deixam 'ficar por baixo'.

Algumas de suas ações podem conduzi-las às barras dos tribunais e isso, a depender do sujeito de enunciação (mas também o do enunciado), não constitui um desvio moral. O que não se confunde com o velho estereótipo litorâneo ou sudestino segundo o qual os sertanejos toleram o homicídio, mas não o roubo. Essa é uma caracterização muito mais adequada a qualquer burguês sulista do que às pessoas que fazem parte do meu cotidiano de pesquisa. A vergonha da prisão, do julgamento e da eventual condenação é compensada (não por uma tolerância qualquer), mas pela galhardia de defender-se a si e sua família. A vingança de família é um modo de impedir a confiscação do emprego da justiça pela família. Normalmente, portanto, alega-se a injustiça como motivação para a vingança.

O conjunto de motivações e justificativas para a ação da vingança é formado ainda pelo esquema vergonha-coragem. Retomarei esse aspecto no final do artigo mas vale adiantar que vergonha pode ter o mesmo sentido de coragem, quer dizer, no sentido corrente em que se empregam 'você não tem vergonha?' e 'é preciso ter coragem para'. A falta de atitude para agir adequada ou corretamente ou, ainda, no sentido de covardia. Ao receber o pagamento de uma senhora idosa que viajou em seu carro, um motorista se desculpou dizendo que não é 'falta de coragem [dele], não', querendo dizer que não era cobardia, no sentido de avarícia. Assim, para encontrar o mesmo sentido de coragem, sob este emprego, vergonha exige uma negativa: não ter vergonha. Ao passo que vergonha e coragem também são usadas no sentido oposto, o de bravura: 'existem duas coragens. A de vingar um parente morto e a de ver quem o matou ainda vivo e contando história nas cachaças e na ponta da rua', disse-me uma mulher cuja família esteve envolvida num processo longo e sangrento de vingança diante do meu espanto da coragem dos seus parentes durante a briga. Do mesmo modo, vergonha podem ser duas: a do estilo de vida do frouxo, a resultante do modo de reagir do valente $e^{4}$. A vergonha neste último sentido motiva, arrasta, impede, enfim, neutralidade diante do insulto ou da agressão física a si, a um parente ou a sua propriedade.

4 No Sul do país, Ayub (2018) mostra avaliações semelhantes das mulheres de Pinhão (PR) a respeito da violência resultante do conflito pela terra. 
Essas definições, oposições e combinações, mesmo quando individuais, referem-se a um coletivo que se congrega pela via do sangue (Marques 2003 e 2013; Villela e Marques 2016). No sertão, sangue é prole, filiação, família, gente de alguém, de alguma descendência. Ele faz perseverar, em continuidade, costumes e hábitos. Faz com que alguém seja brabo ou manso, valente ou frouxo. Assim como é condutor de politica, pois há quem traga 'a política no sangue'. Mas o sangue, apesar das aparências e de um certo aspecto, não é um dado meramente natural; ainda que não seja redutível a uma metáfora nativa. Dado, ele também deve ser feito. Se ele tem essa capacidade de ser purificado, ele também o tem de misturar-se aos outros sangues (Carsten 2013), tornando possível uma quase-escolha do sangue ao qual uma pessoa deve as suas características, as suas obrigações e do qual pode esperar solidariedade. E aqui reside o problema da instabilidade do parentesco sertanejo, como mencionado anteriormente.

\section{A Vingança no Sertão de Pernambuco}

Por ser dado e feito, o sangue e, consequentemente, o parentesco e a família resultam de uma fabricação e manutenção constantes (Villela 2009). Raramente se trata de reação espontânea ao sangue derramado de um parente. Diversas etnografias mostram como em várias partes do mundo onde os esquemas de vingança são corriqueiros, quer dizer, onde existe resistência às confiscações da circulação dos danos sofridos e das compensações exigidas, encontram-se fórmulas diferentes para expressar discursivamente quem deve ou não deve, de quem é exigido ou a quem é interditado, um ato de vingança como modo de cobrar o sangue de um parente. Assim é em várias regiões da África (Evans-Pritchard 1940, Bourdieu 1972, Adler 1980), no Japão e no oriente médio (Abu-Lughod 1986, Chelod 1980), em várias outras partes do Mediterrâneo (Boehm 1983; Black-Michaud 1973; Herzfeld 1985), no Cáucaso (Charachidze 1980). No sertão de Pernambuco a reação de alguém diante da morte de um parente é sempre um motivo de cálculo e especulação porque as relações de parentesco, simultaneamente dadas e fabricadas, são feitas e desfeitas, entre outras coisas como a política eleitoral, pelo próprio esquema da circulação das mortes e das solidariedades (Marques 2002). Pois, vale lembrar, o parentesco é instável, não é uma relação dada de uma vez por todas. A localização de uma pessoa no interior de uma genealogia é, portanto, motivo de debate e controvérsia, decerto, mas sobretudo de convivência e atualização regular dos laços.

Os sistemas de violência foram, já mais de uma vez, associados à teoria da reciprocidade (Girard 1972, Bourdieu 1972, Lacourse 1987, Haidt 2010). O tempo, sob a forma de prazo, é dos mais fortes argumentos para essa associação, sobretudo para Bourdieu (1996). Do mesmo modo, no sertão de Pernambuco o prazo de uma morte devolvida faz variar o tom da vingança, mas é capaz de modificar as dimensões da briga. Porque vingar-se é um problema de cálculo, de especulação e de antecipação; não apenas de retrospecção. A vingança não se dirige meramente ao que ocorreu no passado, ao acúmulo pretérito das mortes ocorridas (essa uma das grandes negligências das teses que ligaram vingança e reciprocidade). Ela é prospectiva. A quem se deve matar para vingar-se adequadamente? Para infligir não apenas a mesma quantidade de dor ao inimigo, mas também para enfraquecê-lo e não fortalecê-lo? Fortalecê-lo em função de matar uma pessoa cujos parentes, ainda fora da questão, são convocados a 
aliar-se ao seu inimigo ou que ative um parentesco apenas virtual, inscrito meramente nos livros de genealogia que abundam no sertão. Enfraquecê-lo, matando uma pessoa que sustenta a querela, seja por sua riqueza financeira, seja por sua atividade profissional, por suas relações político-jurídicas, seja por sua bravura e pelo temor que inspira: sua fama. Palavra que exige explicaçóes que aparecerão mais adequadamente no final do artigo.

Necessitada de armas e de outros instrumentos, materiais e humanos, o esquema da vingança de sangue no sertão de Pernambuco é meio de conexão entre ilegalismos diversos. Famílias em questão, quando dispõem de recursos, contratam, mão-de-obra armada (pistoleiros), ou atraem-na, mesmo sem remuneração (micro-grupos de base familiar sem recursos que conduzem as suas próprias questões). A clandestinidade, pela fuga da justiça e da polícia, leva muitos jovens a cometerem outros tipos de crimes, como roubo de carga e tráfico de drogas, hoje, ou a 'caírem no cangaço', no passado, para terem acesso a recursos financeiros, armas e munição e manterem vivas suas questões. Esse percurso conduz à tão antiga quanto viva noção de desmantelo. Como espero mostrar, essa noção central para a avaliação pública de indivíduos e famílias é igualmente incontornável para a crítica à perseguição pelos regimes punitivos de Estado.

Desmantelo é adjetivo sempre negativo. Uma pessoa ou uma família é desmantelado (assim mesmo, no masculino), mas uma cadeira, um eletrodoméstico também o são, desde que quebrada ou com defeito. O desmantelo humano é moral. Um pai alcóolatra, preguiçoso ou mulherengo; filhas e filhos desobedientes; esposas infiéis e preguiçosas são condutas que recebem a avaliação de desmantelo. Gente que não gosta de trabalho é desmantelado, assim, por exemplo, os políticos. Desmantelados e desmanteladas são os que não mantêm seu asseio pessoal, a limpeza da sua casa e, na área rural, o do seu roçado. Mas alguém que um dia "caiu no cangaço", para os tempos antigos, ou, hoje, que se tornou perseguido da justiça, por qualquer motivo, é também um desmantelado.

Aí reside o problema, já formulado anteriormente, mas agora retomado já de posse de dados etnográficos: como, diante dessa avaliação moral que diz de alguém envolvido em atos violentos (em mortes, em perseguição jurídica e policial) um desmantelado (noção que recebe invariavelmente um sinal negativo), é possível sentir orgulho ou achar graça num ancestral citado num processo jurídico? Sobretudo quando, conforme já mencionei, uma pessoa é sempre composta pelos sangues de seus antepassados, quer dizer, de seus mortos.

Os dados de que disponho permitem avançar algumas hipóteses a esse respeito, conforme apontei em um artigo inicial desse ciclo de pesquisas acerca das implicações da vida dos mortos nas vidas dos vivos (Villela 2016). A ideia é que existe uma mnemotecnologia política e alopoiética dos vivos por meio dos mortos, um tema já bastante estudado por ao menos três antropólogas (Verdery 1999, Sanjurjo 2013 e Petrovic-Staeger 2011). A esse esquema dei o nome de "thanasimologia política" que corresponde à construção dos ancestrais por meio da palavra dita ou escrita dos vivos que se encaixam sob a sua descendência concedendo simultaneamente relevância existencial a si mesmos e a seus mortos.

Muitas são as variações da thanasimologia, o dizer (e escrever) os mortos, pois se pode efetuar essas tarefas de várias formas. No sertão, eles podem ser cantados, descritos, redivivos em seus filhos e netos e engrandecidos por eles, em atos, em palavras e em celebrações rituais. E podem receber essas 
breves peças que são chamadas de biografias. Elas geralmente cabem em espaços entre três e cinco páginas e são incluídas nessas enormes listas de genealogias que abundam na região. Mas apenas as figuras destacadas são dignas de receber uma biografia. Para isso, é necessário que tenham feitos ou ditos extraordinários geralmente na constituição política do município, no combate a inimigos nacionais ou estaduais em defesa da sua terra e do seu povo. Por conseguinte, na valentia (no sentido de destemor) dos seus atos e das suas palavras.

A história municipal de vários dos municípios sertanejos, portanto, é a das lutas armadas contra as populações originárias, os governos e os bandoleiros. O sertão constitui-se como habitado por um “povo em armas" (Villela 2004 e 2011) antes do que por um conjunto de coronéis monopolistas. Ademais, a história dos municípios é coalhada pela do cangaço. Alguns dos mais importantes cangaceiros do século XIX e XX são filhos da região do Pajeú, do Moxotó e do Navio. As armas são parte integrante ao menos das vidas dos antepassados dos vivos do presente. Atos de bravura, de valentia, mesmo que levem a uma ou a várias mortes, são entendidas como heroicas, desde que relatados ou reproduzidos pela parte que lhe é ou se considera parente e desde que estejam afastadas no tempo. A relevância da vida das armas, conquanto pretérita, enfim, confere à existência no presente a exigência de avaliação ambígua em relação às atitudes violentas. O que, por sua vez, revela uma certa relação política com o passado. Veremos que nos municípios do sertão de Pernambuco, onde faço pesquisa, o passado é politizado, sobretudo quando a tarefa é construir e manter as ligações genealógicas das grandes famílias. A lembrança familiar, portanto, é problema político e vice-versa.

\section{Vingança, Passado e Futuro}

Conforme escrevi noutro lugar (Villela 2007) e como confirmado mais recentemente (Pereira 2017), muitos sertanejos, sobretudo os e as mais velhas, estabelecem com o passado uma dupla relação. Por um lado, o passado é vivido na chave da "nostalgia estrutural" (Herzfeld 1984), quer dizer, o tempo da fartura, da retidão moral, das hierarquias ajustadas, do respeito e da atenção. Por outro, é entendido como o tempo do atraso e da ignorância, sintetizado muitas vezes como 'o tempo do carrancismo'. A ignorância pode ser compreendida como intolerância, sobretudo moral. Assim, fechar uma passagem, deixar cães morderem a criação, ou 'animais inteiros' (cavalgaduras não castradas) cobrirem uma égua, desavenças de fundo econômico, como dívidas e créditos mal resolvidos e, causa maior, a morte de um parente, eram, e são, entendidos como insultos por pessoas consideradas ignorantes. $\mathrm{O}$ insulto, por sua vez, é a invasão de um território existencial que contraria ou incomoda a afirmação de um modo de vida e que põe em risco a sua possibilidade de efetuação.

A ignorância, portanto, é uma qualidade de quem, mesmo vivendo nos dias atuais, é atrasado, e cuja conduta é anacrônica. É a forma sertaneja de conceituar o que Fabian chamou de alocronia (Fabian 1983). São pessoas cuja existência adequa-se a um tempo que não é mais o presente, embora sejam coetâneas. Ela corresponde à hipersensibilidade ao apelo dos parentes mortos em consequência do esquema das vinganças de sangue, cuja fórmula discursiva é acusar uma pessoa de 'não aguentar nada'. As pessoas que 'não aguentam nada', excessivamente suscetíveis às provocações provenientes do mundo, gente que 
é braba, cuja fama em geral é proveniente do seu sangue e lugar de nascimento, atualmente pode receber a valoração negativa de ignorantes ${ }^{5}$. Por outro lado, a lassidão física e moral para a resposta a um insulto, a recusa em reagir ao apelo da vergonha, levava e pode levar hoje a consequências graves no curso da vida dos vivos. Como vimos, nunca alguém é um indivíduo sintético no sertão. Ele é o efeito do que foram os seus ancestrais, quer dizer, os seus mortos e pode ser decomposto por quem sabe destrinchar o parentesco, as e os genealogistas; um dos modos de apelar aos mortos no sertão de Pernambuco.

Os mortos apelam aos vivos e os vivos aos mortos de diversas formas no sertão de Pernambuco. Uma delas é a da influência política (Villela 2016). Não se faz política sem que se opere algum tipo de inserção numa ancestralidade política. Daí que a memória de família exija a participação da política. A relevância da política no sangue é expressa no esforço de as pessoas ou certa linhagem inserirem-se ou criarem para si próprias uma ancestralidade política ou um tronco (muito sinteticamente, um ancestral de biografia destacada) cuja relevância seja emanada para os vivos que descendem dela. Uma outra forma de apelar dos mortos, extinta em ambiente urbano segundo os dados de minha mais recente permanência no sertão, era a das almas que vinham solicitar favores, matar as saudades ou despedirem-se adequadamente de seu parentes. Outra, ainda, a da homenagem aos mortos das mais diversas formas, que atualmente cresce a cada dia em volume e intensidade. Nenhuma dessas modalidades será trabalhada neste artigo.

A vingança é uma das formas de os mortos apelarem à ação dos vivos em sua homenagem, uma palavra que nunca cheguei a usar até hoje para esse caso, mas que talvez seja apropriada. A vingança de família não é apenas a tentativa de resguarda-se moralmente das ameaças da vida em concorrência como é a do sertão de Pernambuco, conquanto esse tema seja fundamental, conforme acabei de afirmar. Não é apenas um meio de mostrar-se protegido por si mesmo e pelos seus dos ataques de adversários e inimigos atuais e possíveis. Vingar um parente morto, arriscar a sua vida e as de muitas outras pessoas queridas, cujo cálculo de risco é impreciso e imprevisível, aniquilar muitas vezes a vida econômica de uma casa, envolver-se com a vida do crime, arriscar-se à prisão e à vida carcerária, é a expressão da enorme solidariedade e do amor familiar. É preciso revelar um amor intenso e enorme respeito para sacrificar-se em nome de um parente morto. 'Questão é miséria' é uma fórmula recorrente para expressar a rejeição sertaneja às brigas e às dificuldades econômicas que acarretam. Lembremos, a vida das armas conduz à clandestinidade e, portanto, à impossibilidade de fixar residência e trabalho. Questão, portanto, é desmantelo, uma noção que conduz à condenação moral.

Em contrapartida, a ideia de que salientar a vida de um ancestral reverte-se para quem o salienta é válida para o processo das vinganças. Afinal, sabemos já, uma pessoa é, caso não reverta ou interceda negativamente, o efeito da mistura dos sangues dos seus ancestrais. Acorrer ao chamado de um parente

5 O parentesco, no sertão é Pernambuco, é sempre uma composição da família e do território. Um sobrenome, segmentado em sub-sobrenomes, em patronímicos e matronímicos, em casas, sempre será acompanhado da segmentação territorial que lhe corresponde. Na associação sobrenome território exercem-se as forças da herança da propriedade e da residência pós-matrimonial, assim como as solidariedades cotidianas, sobretudo no ambiente rural, mas também no urbano. Como não há regra de residência e a herança obedece às lei nacionais brasileiras, os desdobramentos são incertos. O que atrai para a nova residência pode ser o que repele na anterior, entre várias possibilidades (a política, a riqueza, a qualidade da terra, as condições de habitação) a vingança. De qualquer modo, alguma inquietação assalta casais grávidos: o que ela(e) vai ser? Quer dizer, como "vai se assinar"? (a esse respeito Villela 2009; Marques 2002). 
morto no esquema das vinganças equivale a engrandecer-se; a incrustar-se mais no interior de uma linhagem ou de um sobrenome; a confirmar a fama deixada pelos ancestrais, quer dizer, os seus mortos.

Nesse sentido, a resposta ao apelo de um morto numa questão é a modalidade mais intensa dentre todas as demais da implicação da vida dos mortos na vida dos vivos. Pode-se dizer que é a única, verdadeiramente, que arranca o vivo do seu caminho cotidiano e faz para ele um novo destino, mesmo que seja o da perdição e do desmantelo. Responder ao sangue derramado de um parente justifica a avaliação ambígua dos atos violentos, já que conduz à perseguição da justiça e da polícia e à clandestinidade. Justifica até a inapelável qualidade negativa do desmantelo. A resposta ao apelo de um morto ou de vários mortos cujo sangue derramado é reconhecidamente por si e pelos demais o mesmo que corre nas veias de quem o vai vingar, ao longo de décadas no sertão de Pernambuco é, portanto, uma preocupação familiar e de parentesco que em certos casos assume proporções capazes de mudar os rumos da gestão pública da segurança e da ordem, como veremos a seguir.

\section{Vingança de Família e Política}

A proposta mais geral da pesquisa com os mortos justifica-se prioritariamente pela compreensão possível da relevância entre administração da política e da justiça e os mortos (Villela 2011; Villela 2016). Já me referi ao caso de Lampião, mas deveria acrescentar a briga entre os Pereira e os Carvalho em Serra Talhada do fim século XIX à década de 1920 e que funcionou como condição de possibilidade para o cangaço de Virgulino Ferreira (Mello 1985 e 1993; Lira 1990; Macedo 1962 e 1980, Chandler 1981). Pereiras e Carvalhos competiam pelo mando eleitoral da antiga Villa Bela desde o Segundo Reinado. Em 1907 ocorreu a morte de um Pereira e, segundo conta a tradição, a pendenga iniciou-se angariando muitos recursos financeiros e humanos. Alguns ataques chegaram a reunir bandos de mais de cem homens armados conforme se vê nos processos que chegaram até os nossos dias. Muitos deles Pereiras de sobrenome e das ramificações de sub-sobrenomes matronímicos, patronímicos e toponímicos, mas diversos outros provenientes de outras famílias, sem recursos nem sobrenome (pois o sobrenome é um recurso), cujos integrantes procuravam nessa questão abrigo e recursos para as suas próprias brigas ${ }^{6}$. O microgrupo dos irmãos Ferreira, entre eles o futuro Lampião, era apenas um deles. Até que, promovido a chefe de bando, Virgulino transformou as inimizades familiares em inimizades contra as forças policiais. Seu poderio hiperbolizou-se a tal ponto que o único lugar de abrigo para os microgrupos intrigados com ele eram a Forças Volantes criadas para impedir o avanço do "banditismo no interior". O objetivo desses microgrupos era sobretudo, mas não apenas, o de responder ao apelo dos seus mortos e vingarem-nos contra quem lhes tirou a vida em combate. Assim, as exigências da gestão

6 Os processos do Segundo Reinado, do Império e da Primeira República deixam claro que o sobrenome é uma marca das grandes famílias. Nas demais, o laço que identifica o parentesco, sobretudo o de filiação e de siblings é antes o segundo nome, herdado do pai ou de um avô quando dos rapazes, da mãe ou de uma avó, quando das moças. Os sobrenomes variavam bastante de irmão a irmão, de irmã a irmã. Alguns desses segundos nomes, em certos casos, tornaram-se sobrenomes fixos com o passar das décadas e com a mudança das leis de nominação. 
da ordem pública sequestraram a gestão das relações familiares da vingança ao mesmo tempo em que foram colonizadas por elas e as impulsionaram.

Algumas das questões e vinganças de sangue no sertão de Pernambuco assumem proporções enormes e duram, em certos casos, décadas. Marques (2003) mostra algumas delas: em que uma tentativa de pacificação foi feita na Assembleia Legislativa do estado; em que dezenas de pessoas foram mortas, incluindo aí dois prefeitos entre as décadas de 1980 e 1990 e cujos desdobramentos ainda estão em vigor ou em vias de reaquecimento; em que uma briga de família foi tragada pelos interesses policiais e transformou-se num grande escândalo financeiro da década de 1980. Tratam-se, portanto, de eventos de média e longa duração de fortes impactos não só no cotidiano municipal, como também estadual e de repercussão nacional. Eventos que, como o que aconteceu entre Benvindos e Araquan, no município de Belém de São Francisco ensejou, em 1997, ortogonalmente ao tráfico de maconha e assaltos nas estradas, a criação da Companhia Independente de Operações e Sobrevivência na Área de Caatinga (Ciosac), 'polícia e elite' extinta em 2015.

O impacto do apelo dos mortos nas vidas dos vivos extravasa o que resulta da reação de seus parentes, próximos e distantes. Ele torna-se um problema de gestão pública da violência. $\mathrm{O}$ cangaço de Lampião é o exemplo mais exuberante e mais célebre, mas não o único, como se vê no parágrafo anterior, que permite compreender o alcance desse enunciado. As intrigas e as questóes multiplicam-se e fazem parte do cotidiano sertanejo; elas fazem os microgrupos de base familiar conjugarem-se em torno de grandes famílias, pois é preciso, vale retomar esse argumento, a conjuração de recursos para que se mantenha a questão em curso. Elas não são, portanto, addenda. Esses recursos, em caso de microgrupos de poucas posses, são provenientes das grandes questões que lhes servem, entre outras coisas, de refúgio e proteção contra a ação da polícia e da justiça. Eles se acoplam a outros sob a proteção de uma grande família em questão contra uma outra. Assim foram formados os grandes bandos do cangaço do fim do XIX até a década de 1920. Assim são conformados os grupos armados, conquanto não sob a forma de bandos, atualmente. Acrescente-se a isso a adesão ao tráfico de drogas, ao roubo de cargas e, em casos extremos, de bancos.

Assim, as brigas de família no sertão de Pernambuco, quer dizer, o apelo dos mortos e seu impacto na vida dos vivos, provocam a necessidade de restruturação no âmbito da justiça e da segurança pública (Villela 2011). Muito foi escrito sobre violência e segurança pública no Brasil nas últimas quase quatro décadas (Marques 2018), de modo que não há espaço no âmbito deste artigo para sintetizar as tendências e configurações que os debates assumiram. Não obstante, muito dessa discussão de o que fazer com o que se passou a chamar-se criminalidade violenta foi estimulada pelo 'banditismo no interior', conforme a chamavam o jornalismo, e os políticos da capital pernambucana em geral e os juristas e especialistas da Faculdade de Direito de Recife, em particular, a partir da última década do século XIX (Villela 2011).

Na época da briga de Serra Talhada e, anteriormente, na época do lendário cangaceiro Antonio Silvino (Lewin 1979), foram desenvolvidos vários planos pelo governo de Pernambuco, entre eles, a criação das famosas Forças Volantes que se fortaleceram e prosperaram até o início da década de 1940. $\mathrm{Na}$ época de Lampião, firmaram-se vários acordos multi-estaduais coordenando polícias de até cinco 
estados, já na década de 1920. Em 2004, as brigas de família, o cultivo da maconha e o roubo de cargas e de bancos, levaram à constituição de um esquadrão de elite na PMPE, a já citada Ciosac.

Acrescente-se à mobilização do aparelho da segurança pública, o funcionamento da justiça e das concepções das execuções penais. Como se sabe, de acordo com as leis brasileiras é o ministério público o responsável por qualquer atentado contra vida. Esse processos são dirimidos diante de um tribunal que requer a presença de um júri popular. Nos municípios onde faço pesquisa de campo os julgamentos de atentados contra a vida marcam uma época do ano que é chamada de "tempo do tribunal". E eles são convocados a julgar homicídios resultantes do esquema das vinganças. São 99 pessoas convocadas por ciclo, das quais 25 são sorteadas com antecipação de sete dias para avaliação da defesa e da promotoria. Das não vetadas, sete são sorteadas 24 horas antes do julgamento.

O "tempo do tribunal” corresponde a dois movimentos simultâneos: 1. o da distribuição da justiça; 2. o das visitas e dos pedidos tanto de parentes das vítimas quanto dos réus dirigidos aos integrantes do júri popular. Detenho-me apenas no segundo ponto que é o mais relevante para meu argumento neste artigo.

Durante o "tempo do tribunal" as antigas e esquecidas relações de parentesco, as velhas solidariedades e favores, mesmo quando desativadas, são recordadas na tentativa de sensibilizar os jurados a votarem em favor de uns ou de outros. O esquema da vingança (e consequentemente o apelo dos mortos) imiscui-se, consequentemente, tanto nos procedimentos da gestão pública da violência quanto nos funcionamentos da justiça. Estudar os mortos no sertão de Pernambuco é também um modo de compreender as dinâmicas da segurança pública e da justiça.

Durante a Primeira República muitos dos grandes juristas da Faculdade de Direito de Recife atacaram a 'instituição democrática do júri popular'. Não por ser democrática, mas por ser popular. $\mathrm{O}$ 'juiz leigo', defendiam muitos, não está preparado para manter separadas, sobretudo nas 'comarcas do interior', o que é do privado e o que é da administração e distribuição pública da justiça. Ademais, sustentavam eles, desprotegidos da polícia e da justiça, desprovidos de direitos, empobrecidos, eram alvos fáceis dos 'senhores do baraço e do cutelo' das 'longínquas paragens ainda selvagens do sertão'. Isso, sustentavam ainda os especialistas, na melhor das hipóteses. Na pior, eram cúmplices em acobertar, sob as barbas dos juízes togados, o banditismo que grassava no interior. De uma certa forma, a invenção moderna do Sertão Pernambucano passa pela crítica jurídica de Recife ${ }^{7}$.

As avaliações dos juristas eram apenas imprecisas e deliberadamente posicionadas no lado inexistente da vida. Ao inventar um sertão miserável, selvagem, corrupto e inculto, como se falassem diretamente desde uma cidade sem violência, de relações puramente jurídicas sem a interferência da necessidade, das vontades e dos desejos, os relatórios que produziam inventavam junto com esse mundo um outro, de repressão brutal e iníqua a $500 \mathrm{~km}$ dali. Sem, no entanto, delivrar o cenário que mal compreendiam de seus graves problemas centenários. Como poderiam saber esses homens o que se passava num mundo cuja maior proximidade terá sido a de conhecer um juiz, um promotor que de passagem

7 Uma outra vertente dessa invenção, por meio das obras contra a seca, encontra-se em Luchesi (2017). 
serviram no sertão? De testemunho presente, vi um desses pares exigindo que motoristas que serviriam ao TRE numa eleição municipal que não levassem parentes em seus carros, ameaçando apená-los em crime federal. Andariam com os carros meio vazios, nesse caso, a depender da genealogia que estabelecesse as conexões de ascendência.

Como na política eleitoral o termo nepotismo é fraco para descrever relações em que política e família constroem-se uma a outra, como ocorre em alguns municípios do sertão, não será possível pensar o funcionamento do júri de um modo capaz de apagar todas as memórias e solidariedades e inimizades pregressas ao dia de um julgamento. Desculpem retomar: as pessoas no sertão reconhecem-se feitas dos seus mortos. Sem essas relações não são mais pessoas. Não são mais reconhecíveis. Não seriam mais existentes, portanto. E um júri é composto por sete existentes. Reais, não pertencentes à classe dos objetos intencionais, para usar a velha expressão de Franz Brentano. Por esse motivo, as pessoas podem e devem recorrer à memória, ao sangue, ao parentesco, às dívidas e créditos que se condensam em torno desse conceitos, para proteger os seus de uma condenação. Não o fizessem, seriam elas e eles mesmos condenados por desmantelo. Seria falta de coragem, mas seria preciso ter coragem para ver um filho, um irmão, um pai, seguir para o seu julgamento sem nada fazer por ele ${ }^{8}$.

\section{Vergonha e Coragem, ainda}

A finada antropologia do Mediterrâneo conferiu ao par honra e vergonha a garantia da existência de uma unidade geográfica de comparação e análise. Durante três décadas o par perseverou, mas não resistiu às críticas etnográficas dos anos 80 (e.g. Herzfeld 1980; Wikan 1984; Abu-Lughod 1986). Seu falecimento atestou o óbito da unidade e de sua correspondente antropologia. Par de opostos complementares, uma de suas causa mortis foi a suspeita de ser apenas uma artimanha antropológica que confundia conceito analítico e dado etnográfico, segundo um de seus mais ácidos críticos (Herzfeld 1980), mas também de ignorar as sutilezas dos conceitos locais sob os quais honra ou vergonha nem sempre formavam pares de opostos um com o outro ou apenas um com o outro.

O sertão de Pernambuco foi desde sempre um bom lugar para a inspeção da eficácia desse par, sobretudo quando se tratou do problema dos chamados crimes de honra, dos que servem para lavar a honra com o detergente do sangue. Pois, destaquei desde o início de minha pesquisa, a palavra honra não forma ali par com a vergonha. Ela sequer é mencionada, a não ser como um modo de traduzir quase juridicamente para forasteiros sudestinos ou litorâneos as motivações locais para as vinganças de família.

Coragem e vergonha não formam um par. Formam uma consistência, como se fossem atributos um do outro, cujos sentidos se flexibilizam e derivam de um ao outro. E comportam a eficácia de um esquema que desliza do ambiente propriamente doméstico, o das casas, aos microgrupos de base fami-

8 O tema da participação das mulheres nos esquemas de vingança é vasto e complexo. Elas aparecem como motivos (Villela 2004), como agentes, como maquinadoras, como neutralizadoras (Marques 2002). Mas não são reclamadas como mortas, porque, afinal, tanto no passado, quanto atualmente é extremamente raro que se matem mulheres em vinganças de família. 
liar, ao do sobrenome e, enfim, ao da administração política da segurança e da justiça. E provocam a ambiguidade da memória da vida das armas no sertão de Pernambuco, o tema final deste artigo.

Conforme vimos acima, apenas as figuras destacadas recebem biografias nas vastas listagens de nomes que compõem as inúmeras genealogias elaboradas em diversos municípios sertanejos, mas sobretudo em Floresta. Vimos também que essas figuras assumem a posição de troncos, quer dizem, de fundadores de uma linhagem no interior de um sobrenome. Eles são pontos de segmentação que raramente, no entanto, implicam uma fissão no contínuo da genealogia. Vimos, ainda, que em muitos casos a condição de tronco é conquistada por ditos ou feitos na ordem da valentia, mas também da brabeza; por outras palavras, da capacidade de responder a um insulto ou a um desafio de um modo cuja resposta mesma implique no risco de sua vida. Por capacidade é preciso entender-se os meios, os instrumentos, os recursos para efetuar a reação, a resposta à altura, a toda eventualidade.

Por isso, será preciso despender algumas palavras a respeito do que se pode entender como recursos nessas circunstâncias etnográficas. Ao que se pode recorrer, sob essas circunstâncias é muita coisa e, portanto, será conveniente circunscrevermos apenas alguns, mais correntes e recorrentes. O prestígio é um deles. Caráter constantemente em vias de demonstração e disputa, 'ter prestígio' é obter favores, atenções, serviços, sobretudo para os outros. Uma pessoa de prestígio efetua em certos casos, os que envolvem a política e a administração pública, brokerage ou gatekeeping, para usar as expressões da velha antropologia política processualista. Pode-se ter apenas prestígio junto a alguém e não a todos. Pode-se ter prestígio na esfera jurídico-policial, o que evita prisões vexaminosas ou apreensão de armas. Esse aspecto é de tal modo relevante que um homem chegou ao ponto de dizer que "a ordem se acabou no ano de 70", o que queria dizer que os políticos perderam o prestígio de reaverem as armas de seus protegidos e de os tirarem imediatamente da prisão em Serra Talhada. O prestígio pode-se circunscrever no ambiente do sobrenome, servindo para arrefecer conflitos, mediar acordos de pacificação e garantir o seu cumprimento por meio de sua presença na hora dos compromissos. Para ter prestígio, a despeito do ambiente em que é reconhecido e demonstrado, é preciso ter coragem e também vergonha.

Coragem, no sentido de destemor e no de obrigação empática, e vergonha, no sentido de enfrentar os desafios a despeito do preço que se tenha de pagar, justificam em grande medida os atos violentos. Ambos fazem os sertanejos compreenderem perfeitamente o motivo de alguém aderir à vida das armas, de abandonar-se no cangaço, de refugiar-se na clandestinidade, de opor-se às autoridades legalmente constituídas, mas também às forças que, por meio de um insulto, desejaram negar-lhes a possibilidade de engajarem-se num modo de vida ou que os transformaram tão brutalmente ao ponto de redesenharem os seus destinos.

Jorge Vilella é doutor em Antropologia Social pelo PPGAS/Museu Nacional (UFRJ) e professor de Antropologia na UFSCar. É também bolsista PQ2, do CNPq. 


\section{REFERÊNCIAS BIBLIOGRÁFICAS}

ABU-LUGOHD, Lila. 1986. Veiled Sentiments. Honor and poetry in a Bedouin Society. Berkeley: University of California Press.

ADLER, Alfred. 1980. "La Vengeance du Sang chez les Moudang du Tchad”. In: La Vengeance. Vol I. Raymond Verdier (org.). Paris: Cujas.

BLACK-MICHAUD, Jacob. 1973. Cohesive Force. Feud in the Mediterranean and Middle East. Nova Iorque: St. Martin's Press.

BLOK, Anton. 1974. The Mafia of a Sicilian Village, 1860-1960. Illinois: Waveland Press.

BEVILAQUA, Ciméa Barbato. 2003. "Etnografia do Estado: algumas questões metodológicas e éticas". Campos, 3: 51-64.

BOHEM, Christopher. 1984. Bllod Revenge. The enactment and management of conflict in Montenegro and other tribal societies. Filadelfia: University of Pensylvania Press.

BOUDIEU, Pierre 1972. “Trois Études d'Ethnologie Kabyle”. In: Esquisse d'une Théorie de la Pratique. Paris: Droz.

Bourdieu, Pierre. 1996. "Marginalia. Algumas notas adicionais sobre o dom"> Mana.2.2.

BUCKLAND, Michael K. 1997. "What is a document?". Journal American Social Informational Science (48):804-9.

CARSTEN, Janet. 2013. “Blood will Out”. JRAI. V 19 Special Issue.

CHANDLER, Raymond. 1981. Lampião, o Rei dos Cangaceiros. Rio de Janeiro: Paz e Terra.

CHARACHIDZE, Georges. 1980. “Types de Vendetta au Caucase”. In: La Vengeance.

CHELOD, Joseph. 1980. "Équilibre et Parité dans la Vengeance du Sang chez les Bédouins de Jourdanie". In: La Vengeance.

CUNHA, Olívia Maria Gomes da. 2004. “Tempo imperfeito: uma etnografia do arquivo”. Mana, 10(2): 287-322.

EVANS-PRITCHARD, E 1940. The Nuer. Londres: Oxford University Press.

EVANS-PRITCHARD, E. E Fortes, M. (orgs). 1940 Sistemas Politicos Africanos. Lisboa: Calouste Gulbenkian.

FABIAN, Johannes. 1983. Time and the Other. Nova Iorque: Columbia University Press.

GIRARD, Renné. 1972. La Violence et le Sacré. Paris: Grasset e Fasguelle.

HAIDT, Jonathan 2010. "Réciprocité et Vengeance par Reciprocité”. In: Hippothese du Bonheur. Jonathan Haidt (org.). Paris: Mardaga.

HERZFELD, Michael. "'Honor and Shame: some problems in the comparative analysis of moral systems". Man, 15.

1985. The Poetics of Manhood. Princeton: Princeton University Press.

HULL, Matthew S. 2012. "Documents and bureaucracy”. Annual Review of Anthropology, 41: 251-67.

LACOURSE, Josée 1987. "Réciprocité Positive et Reciprocité Negative. De Mauss à Girard".

Cahiers Internationaux de Sociologie, 83.

LANDE, Carl. 1977. "Introduction: the dyadic basis of clientelismo". In: Friends, Followers and Fac- 
tions. S. W. Stmith, L. Guasti, C. Landé e J. Scott (orgs). Berkely: California Universty Press. LATOUr, Bruno. 1999. Politiques de la Nature. Paris: La Decouverte.

LEWIN, Linda. 1979. "The Oligarquical Limitations of Social Banditry in Brasil: the case of the 'good thief” Antonio Silvino". Past and Present. 82.

LIRA, João G. 1990. Lampião. Memórias de um soldado volante. Recife: Fundarpe.

LUCHESI, Fernanda. 2017. O Feijão de Zé Américo. Terra, trabalho e deslocamento nas politicas contra as secas. Tese de Doutorado. PPGAS-USP.

MACEDO, Nertan. 1962. Lampião: capitão Virgulino Ferreira. Rio de Janeiro: Renes. 1980. Sinhô Pereira. O comandante de Lampião. Rio de Janeiro: Renes.

MARQUES, Ana Claudia 2003. Intrigas e Questóes. Rio de Janeiro: Relume Dumará. 2013. "Founders, Ancestors and Enemies".JRAI. 19.4.

MAUSS, Marcel 1902.

1969 [1924]. "Gift-gift”. In Oeuvres 3. Victor Karady (org.). Paris: Minuit. 1993 [1925]. "Essai sur le Don”. In: Sociologie et Anthropologie. Paris: PUF.

MELLO, Frederico P. 1985. Guerreiros do Sol. Recife: Massangana.

1993. Quem foi Lampião? Recife: Stahli.

MIDLETON, John e Tait, David 1970 [1948]. Tribes Without Rulers. Studies in AFrican Segmentary Systems. Londres: Routledge and Kegan Paul.

MORAWSKA, Catarina 2014. Os Enleios da Tarrafa. São Carlos: EdUFSCar.

MUNHOZ, Sara. 2017. O Governo dos Meninos. São Carlos: EdUFSCar.

OTTERBEIN, Keith. 1994. Feuding and Warfare. Amsterdã: OPA.

PEREIRA, Renan 2017. Rastros e Memórias: etnografia dos vaqueiros do sertão (Floresta). Dissertacão de Mestrado. PPGAS-UFSCar.

PETROVIC-STEAGER, Maja. 2011 “Anathomizing Conflict”. In: Social Bodies. H. Lambert e M. McDonald (orgs.). Oxford: Berghan Books.

RADCLIFFE-BROWN, Alfred R. S/D [1940]. “Prefácio”. In: Sistemas Políticos Africanos. E. Evans-Pritchard e Meyer Fortes (orgs.). Lisboa: Calouste Gulbenkian.

RILES, Annelise. 2006. "[Deadlines]: Removing the Brackets on Politics in Bureaucratic and Anthropological Analysis". RILES, Annelise (ed.) Documents: Artifacts of Modern Knowledge. Ann Arbor: The University of Chicago Press.

SANJURJO, Liliana 2013. Sangue, Identidade e Verdade: memórias sobre o passado ditatorial argentino. Tese de Doutorado. PPGAS-Unicamp.

WIKAN, Uni 1984. "Honor and Shame. A Contestable Pair". Man, 19.4.

VERDERY, Katherine 1999. Political Lives of Dead Bodies.. Nova Iorque: Columbia University Press VILLELA, Jorge Mattar. 2004. O Povo em Armas. Violência e Politica no Sertão de Pernambuco. Rio de Janeiro: Relume Dumará. 2007. Política e Eleições no Sertão de Pernambuco. O povo em armas. Campinas: Pontes. 2009. “Família como Grupo? Política como Agrupamento?”. Revista de Antropologia 52.1. 2011. Ordem Pública e Segurança Individual. São Carlos: EdUFSCar. 
2015. “Os Vivos e os Mortos na Política do Sertão de Pernambuco". Revista de História. 173.

VILLELA, Jorge e MARQUES, Ana Claudia 2016. "Le Sang et la Politique”. Anthropologica. 58.2. ZEITLYN, David. 2012. "Anthropology in and of the Archives: Possible Futures and Contingent Pasts. Archives as Anthropological Surrogates”. Annual Review of Anthropology, (41): 461-480. 


\section{CORAGEM E VERGONHA. OS MORTOS E A VINGANÇA NO SERTÃO DE PERNAMBUCO}

Resumo: Este artigo avança a hipótese de que os mortos no sertão de Pernambuco, por conta das implicações do esquema de vingança, importam e interferem nos funcionamentos da justiça, por conta do júri popular, mas também na administração pública da violência e da criminalidade em diversos governos estaduais de Pernambuco.

Palavras-chave: antropologia, mortos, vingança, família, Sertão, Pernambuco

\section{COURAGE AND SHAME. THE DEAD AND THE VENGEANCE IN THE SERTÃO DE} PERNAMBUCO, BRASIL

Abstract: This article proposes the hypothesis that, given the implications of the scheme of Family and blood vengeance in the Sertão of Pernambuco, the dead matter and interfere in the workings of justice but also in the public administration of violence and criminality in several state governments in Pernambuco.

Keywords: Vengeance, family, Pernambuco, Brazil, Anthropology

RECEBIDO: $13 / 02 / 2019$

APROVADO: $10 / 04 / 2019$ 